\title{
MAXIMAL EXERCISE STUDIES IN SCOTTISH ATHLETES
}

\author{
A. G. LEITCH, B.Sc., M.R.C.P. and L. CLANCY, B.Sc., M.R.C.P.
}

Department of Medicine, Royal Infirmary, University of Edinburgh

\begin{abstract}
We have studied maximal oxygen uptake, maximal heart rate, maximal exercise ventilation and the ventilatory response to exercise in 24 male and 14 female Scottish athletes. The values for maximal oxygen uptake are similar to those reported in other international studies. In eight athletes repeat measurements of maximal oxygen uptake 7-11 months after the initial study showed no change from the initial values. The values for the ventilatory response to exercise in our athletes were normal. The relationship is discussed between maximal oxygen uptake and ventilatory responses to exercise, hypoxia and hypercapnia and it is suggested that these may be related to athletic event.
\end{abstract}

\section{INTRODUCTION}

The few studies of maximal oxygen uptake $\left(\mathrm{VO}_{2}\right.$ max $)$ in British athletes (Pugh, 1970; Watson \& Devenney, 1972) are not adequate to allow comparison with results obtained from athletes in other countries (Saltin \& Åstrand, 1967; Spryranova \& Pariskova, 1971; Malhotra et al, 1972; Hermansen, 1973; Novak et al, 1973).

We have measured $\mathrm{VO}_{2}$ max, ventilation and heart rate at maximal exercise in 38 Scottish athletes. We repeated these measurements after a further 7-11 months in eight of the athletes. In view of the suggested relationships between $\mathrm{VO}_{2}$ max, chemical drive to breathing and the ventilatory response to exercise (Byrne-Quinn et al, 1971; Rebuck et al, 1972) we have also measured the ventilatory response to exercise in this highly trained group of athletes.

\section{SUBJECTS}

We studied 24 male athletes aged 15-31 years (mean 19.1 ) and 14 female athletes aged 14-30 (mean 19.6). Twenty-two of the athletes represented Scotland in the appropriate age group and six were members of the Senior British Team. Sixteen of the athletes were of high club standard and all 38 athletes were in training for the Scottish National Team. The events represented are shown in Tables I and II, there being a predominance of short and middle distance runners.

\section{METHODS}

The scudies took place in the afternoon at least two hours after a light lunch. The athletes were weighed wearing light running kit and subjected to a medical examination when blood was withdrawn for haemoglobin estimation.

ECG electrodes (Dracard disposable) were applied in standard exercise ECG positions, rate being recorded during the last minute of maximal exercise. Where legible recordings were not obtained for the entire minute a value for heart rate was calculated from more than 15 consecutive complexes in the last minute of exercise. In this way, values for maximum heart rate were obtained in all but one subject. $\mathrm{VO}_{2}$ max was measured by a modification of the method of Taylor et al (1955) using a motor driven treadmill. Ventilation and expired gases were measured using apparatus currently in use for sub-maximal exercise studies in patients and normal subjects. The subject breathes through an OtisMcKerrow breathing valve, expired air passing through 4 $\mathrm{cm}$ tubing to a mixing box and from there through a water vapour condenser to a Parkinson-Cowan dry gas meter with a digital read-out. Expired air was sampled from the mixing box in two $50 \mathrm{ml}$ glass syringes driven by a Harvard pump and analysed immediately on a Servomex 101A paramagnetic $\mathrm{O}_{2}$ analyser (Ellis \& Nunn, 1968) and Uras 111 infra-red $\mathrm{CO}_{2}$ analyser (Patrick, 1963) to give $\mathrm{O}_{2}$ and $\mathrm{CO}_{2}$ tensions. The mouthpiece pressures for the valve and tubing only at different expiratory flow rates are shown in Fig. 1 and they are similar to values given by Saltin \& Åstrand (1967) for their maximal exercise breathing system. The addition of the other components in our expiratory circuit leads to a further rise in mouthpiece pressure at a given flow rate which is also shown in Fig. 1.

The athletes exercised at three or four submaximal levels of exercise up to a maximum speed of $11 \mathrm{~km} \mathrm{~h}^{-1}$ and gradient of 9 degrees until a steady state was achieved as indicated by constant ventilation and heart rate for two successive minutes. We then measured ventilation, mixed expired $\mathrm{O}_{2}$ and $\mathrm{CO}_{2}$ tensions and heart rate in the last two minutes of exercise. The athlete then exercised at a higher gradient which we predicted would achieve $\mathrm{VO}_{2}$ max and we made the same measurements in the third minute of exercise. All the subjects were highly motivated as the measurements were part of a "bioprofile" being made for the Scottish National Coach. We relied on their impression that they could not have continued for a further three minutes as indicating that $\mathrm{VO}_{2}$ max had been achieved. The six athletes who 


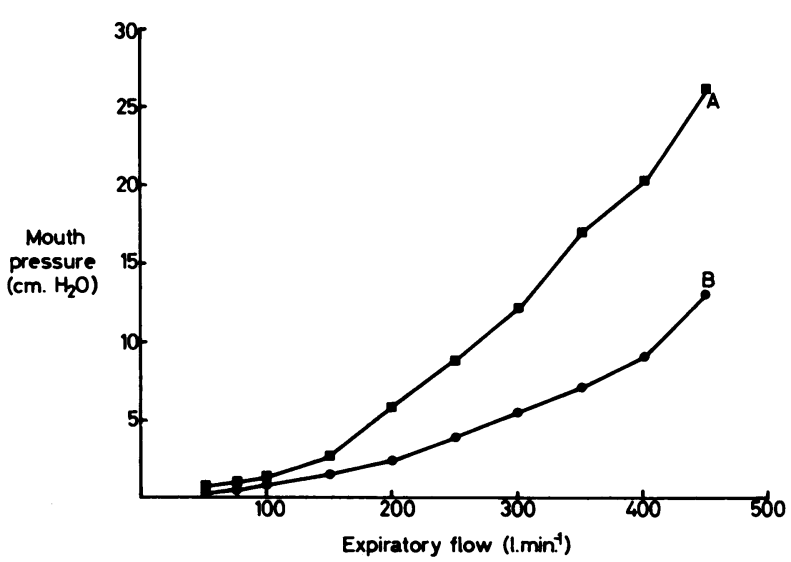

Fig. 1. Relationship between mouth pressure and expiratory flow for

$A-x-x-$ entire breathing system and

$B--$ valve and connecting tubing only (see text) exercised beyond their maximum as defined in this way, achieved no further increase in $\mathrm{VO}_{2}$ max although ventilation was higher indicating marked lactic acidosis. The $\mathrm{O}_{2}$ consumption $\left(\mathrm{VO}_{2}\right)$ was also calculated for the submaximal exercise periods and the linear relationship between ventilation $\left(V_{E}\right)$ and oxygen consumption $\left(\mathrm{VO}_{2}\right)$ calculated by least squares linear regression for three or four simultaneous values in each subject, provided the $\mathrm{VO}_{2}$ was less than $70 \% \mathrm{VO}_{2}$ max, as the relationship is known to be linear in this range ( $\AA$ strand \& Rodahl, 1970).

\section{RESULTS}

Haemoglobin values for all the athletes were within the normal range and there was no significant relationship to $\mathrm{VO}_{2}$ max, maximal ventilation ( $\mathrm{V}_{\mathrm{E}}$ max), maximal heart rate or $\mathrm{VE} / \mathrm{VO}_{2}$.

\begin{tabular}{|c|c|c|c|c|c|c|c|c|c|}
\hline \multirow{2}{*}{ EVENT } & \multirow{2}{*}{$\begin{array}{l}\text { No. of } \\
\text { athletes }\end{array}$} & \multicolumn{2}{|c|}{$\dot{\mathrm{VO}}_{2} \max \mathrm{ml} . \mathrm{kg}^{-1} \min ^{-1}$} & \multicolumn{2}{|c|}{$\dot{\mathrm{V}}_{\mathrm{E}} / \dot{\mathrm{VO}}_{2}$ I. $\min ^{-1} 1^{-1}$} & \multicolumn{2}{|c|}{ Max. heart rate } & \multicolumn{2}{|c|}{$\operatorname{Max} . \dot{V}_{E} \mid \min ^{-1}$} \\
\hline & & Mean & Range & Mean & Range & Mean & Range & Mean & Range \\
\hline $\begin{array}{l}100-200 \text { metres } \\
110 \text { metres hurdles }\end{array}$ & 3 & 48 & $45-50$ & 30 & 1 value only & 187 & $185-190$ & 86 & $67-106$ \\
\hline 400-800 M. & 8 & 57 & $51-66$ & 23 & $18-28$ & 196 & $185-202$ & 94 & $86-110$ \\
\hline $1500 \mathrm{M}$. & 1 & 56 & - & 27 & - & 188 & - & 90 & - \\
\hline Cross Country & 1 & 61 & - & 22 & - & 190 & - & 98 & - \\
\hline Orienteer & 1 & 66 & - & 23 & - & 195 & - & 82 & - \\
\hline
\end{tabular}

Table I. Maximal oxygen uptake $\left(\mathrm{VO}_{2} \max \right)$, Ventilatory response to exercise $\left(\mathrm{VE}_{\mathrm{E}} / \mathrm{VO}_{2}\right)$, Maximal heart rate, and maximal exercise ventilation $\left(V_{E} \max \right)$ in 14 female athletes. Mean values and ranges tabulated by event.

\begin{tabular}{|c|c|c|c|c|c|c|c|c|c|}
\hline \multirow{2}{*}{ EVENTS } & \multirow{2}{*}{$\begin{array}{l}\text { No. of } \\
\text { athletes }\end{array}$} & \multicolumn{2}{|c|}{$\dot{\mathrm{VO}}_{2} \max \mathrm{ml} \mathrm{kg}^{-1} \min ^{-1}$} & \multicolumn{2}{|c|}{$\dot{v}_{E} / \dot{V O}_{2} I \cdot \min ^{-1} 1^{-1}$} & \multicolumn{2}{|c|}{ Max. heart rate } & \multicolumn{2}{|c|}{$\operatorname{Max} . \dot{V}_{E} \mid \min ^{-1}$} \\
\hline & & Mean & Range & Mean & Range & Mean & Range & Mean & Range \\
\hline 100-200 metres & 9 & 52 & $38-60$ & 22 & $18-26$ & 195 & $184-208$ & 99 & $79-131$ \\
\hline $800-1500$ metres & 11 & 67 & $60-75$ & 22 & $18-26$ & 191 & $183-200$ & 112 & $77-143$ \\
\hline 10,000 metres & 1 & 81 & - & 21 & - & 173 & - & 155 & - \\
\hline High Jump & 1 & 57 & - & 22 & - & 194 & - & 106 & - \\
\hline Hammer & 1 & 48 & - & 23 & - & 185 & - & 128 & - \\
\hline Walker & 1 & 57 & - & 21 & - & 195 & - & 121 & - \\
\hline
\end{tabular}

Table II. Maximal oxygen uptake $\left(\mathrm{VO}_{2} \max \right)$, Ventilatory response to exercise $\left(\mathrm{V}_{\mathrm{E}} / \mathrm{VO}_{2}\right)$, Maximal heart rate, and Maximal Exercise Ventilation $\left(V_{E} \max \right)$ in 24 male athletes. Mean values and ranges tabulated by event. 


\section{Women}

The mean values and ranges of $\mathrm{VO}_{2} \max , \mathrm{VE}_{\mathrm{E}} \max$, maximal heart rate and $\mathrm{VE}_{\mathrm{E}} / \mathrm{VO}_{2}$ are shown in Table 1 where the athletes are grouped by athletic event. There was a positive correlation between $\mathrm{VO}_{2}$ max and $\mathrm{V}_{E}$ max by least squares linear regression analysis $(P<$ 0.05). The highest value for $\mathrm{VO}_{2} \max$ was $66 \mathrm{ml}$. min-1 $\mathrm{kg}^{-1}$ for a 17 year old middle distance athlete and also for the 25 year old Scottish Women's Cross Country champion.

\section{Men}

The results in the male athletes are shown in Table II. Again there was a positive correlation between $\mathrm{VO}_{2}$ max and $V_{E} \max$ by least squares linear regression analysis ( $P$ $<0.01)$. The highest value obtained for $\mathrm{VO}_{2} \max$ was $81 \mathrm{~kg}^{-1} \mathrm{~min}^{-1}$ in a 31 year old former Olympic 10,000 metre runner.

\section{Repeat $\mathrm{VO}_{2} \max$}

Fig. 2 shows values of $\mathrm{VO}_{2}$ max obtained using the same methods in 6 female and 2 male athletes 7-11 months after the initial study. When plotted against the initial values the results are very close to the line of identity.

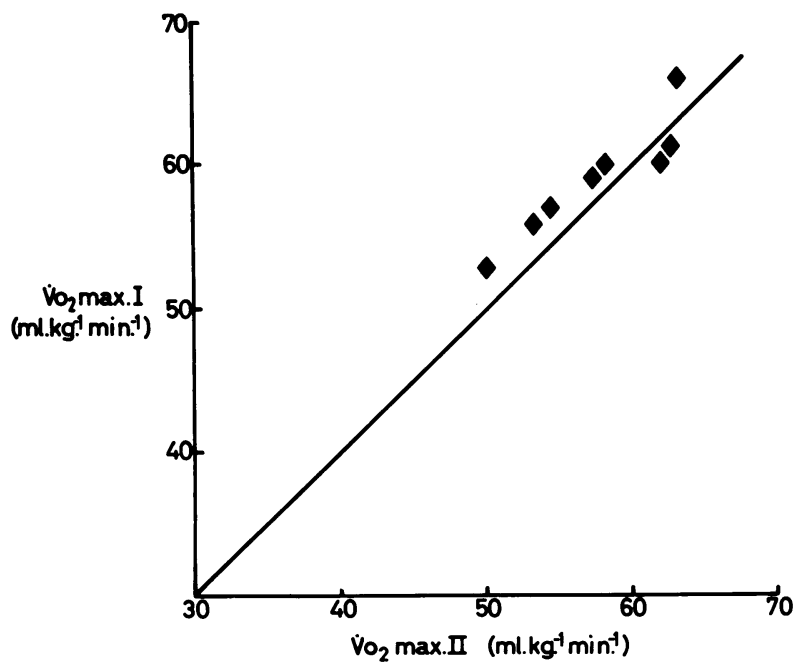

Fig. 2. Repeat $\dot{\mathrm{V}}_{2}$ max studies in 6 female and two male athletes.

$\dot{\mathrm{V}}_{2} \max \mathrm{I}$ - initial study.

$\mathrm{VO}_{2}$ max II - repeat study.

$7-11$ months later.

\section{DISCUSSION}

In any maximal exercise study the pressure-flow characteristics of the breathing system are important. It has been shown that if the external resistance of a breathing system is high enough there will be a marked fall in $V_{E}$ max, $\mathrm{VO}_{2}$ max and exercise performance, (Demedts \& Anthonisen, 1973). The pressure-flow characteristics of our system (Fig. 1) are well below those needed to produce a fall in $\mathrm{VO}_{2}$ max. We might expect a small fall $(<12 \%)$ in $V_{E}$ max as a result of this added resistance (Demedts \& Anthonisen, 1973). A further factor making comparison of our $V_{E} \max$ results with others (e.g. Saltin \& Åstrand, 1967) difficult, is that our measurements were made in the third minute of maximal exercise. Had our athletes exercised for longer (up to 6 minutes) the accumulating metabolic acidosis would have produced a further marked drive to breathing. Indeed, in the six athletes who exercised supramaximally after their maximal exercise, further increases in ventilation were recorded without any additional increase in $\mathrm{VO}_{2}$ max. Nevertheless, our results do show for both sexes the expected relationship between $V_{E} \max$ and $\mathrm{VO}_{2} \max$ (Åstrand, 1952).

The maximal heart rates obtained are in the expected range for maximal exercise (Ekblom \& Hermansen, 1969).

It is known that uphill running on a treadmill produces higher values for $\mathrm{VO}_{2}$ than treadmill running on the level or cycling on a bicycle ergometer (Hermansen, 1973). A further small increase in $\mathrm{VO}_{2}$ max can be obtained with simultaneous arm exercise (Taylor, Buskirk \& Henschel, 1955; Hermansen, 1973) suggesting that $\mathrm{VO}_{2}$ max is determined by the muscle bulk employed in exercise and is not limited by the cardiovascular system. That oxygen transport is not the limiting factor in muscular exercise has been demonstrated (Kaijser, 1970) and it may be that the limiting factor lies in the working muscles.

The values for $\mathrm{VO}_{2}$ max recorded with uphill treadmill running in our subjects are with in the ranges given by Saltin \& Åstrand (1967) and Hermansen (1973) for international Swedish and Norwegian athletes participating in similar events. The value of $81 \mathrm{ml} \mathrm{kg}^{-1} \mathrm{~min}^{-1}$ is the highest recorded in the literature for a British athlete. The 17 year old girl with a $\mathrm{VO}_{2} \max$ of 66 $\mathrm{ml} / \mathrm{kg}^{-1} / \mathrm{min}^{-1}$ on retesting had values of 63 and 64 $\mathrm{ml}^{-1} \min ^{-1}$ and therefore has the highest recorded $\mathrm{VO}_{2}$ max in the world literature for a teenage athlete (Wells et al, 1973).

The repeat values for $\mathrm{VO}_{2}$ max, all performed on short and middle distance athletes, show no improvement over a period of 7-11 months suggesting that these athletes have made no further contribution by training in this period to their aerobic capacity.

Byrne-Quinn et al (1971) have studied $\mathrm{VO}_{2}$ max and ventilatory responses to hypoxia, hypercapnia and exer- 
cise in athletes and controls. As a group the athletes had high $\mathrm{VO}_{2}$ max, low ventilatory responses to hypoxia and hypercapnia and a low ventilatory response to exercise when compared with controls. Rebuck et al (1972) have also shown a direct relationship between the ventilatory responses to hypercapnia and exercise in normal people, although they did not measure $\mathrm{VO}_{2}$ max. We were therefore surprised to find that our group of athletes with high values for $\dot{\mathrm{V}}_{2}$ max had values for the ventilatory response to exercise which did not differ significantly from the mean value in the literature given by Cunningham (1963). We feel that these differences in ventilatory response may lie in the type of athletic event for which the athlete is in training. Our subjects were predominantly short and middle distance athletes, whereas, Byrne-Quinn et al (1971) certainly studied some endurance athletes, although they do not give details. It is known that differences related to athletic event exist for the ventilatory response to hypercapnia. Sprint athletes have high, and endurance athletes low ventilatory responses to $\mathrm{CO}_{2}$ (Rebuck \& Read, 1971). We are tempted to speculate that similar differences may exist for the ventilatory response to exercise. If this were so, we would expect to find the lowest ventilatory responses to exercise in endurance athletes, a group which is not well represented in our study. Our group of short and middle distance athletes had a normal ventilatory response to exercise which is not incompatible with our suggestion. We conclude that further studies of the relationship between $\mathrm{VO}_{2} \max$ and the ventilatory response to exercise are required in subjects participating in a broader spectrum of athletic events. Ideally, such studies should include the measurement of the ventilatory response to hypoxia and hypercapnia.

\section{ACKNOWLEDGEMENTS}

We thank Professor K. W. Donald for laboratory facilities, Dr. D. C. Flenley for helpful advice, Sister McLay and staff nurses for nursing assistance and Miss E. Paxton for technical help.

Without the help of Mr. Frank Dick, the Scottish National Coach, the studies could not have taken place. We acknowledge Miss L. Graham's secretarial help.

\section{REFERENCES}

Åstrand, P-O (1952). Experimental studies of Physical Working Capacity in Relation to Sex and Age, Munksgaard, Copenhagen.

Åstrand, P-O \& Rodahl, K. (1970). Textbook of Work Physiology. McGraw-Hill Book Company.

Byrne-Quinn, E., Weil, J. V., Sodal, I. E., Filley, G. F. \& Glover, R. F. (1971). Ventilatory control in the athlete. Journal of Applied Physiology, 30, 91-98.

Cunningham, D. J. C. (1963). Some quantitative aspects of the regulation of human respiration in exercise. British Medical Bulletin, 19, 25-30.

Demedts, M. \& Anthonisen, N. R. (1973). Effects of increased airway resistance during steady state exercise. Journal of Applied Physiology, 35, 361-366.

Ekblom, B. \& Hermansen, L. (1968). Cardiac output in athletes. Journal of Applied Physiology, 25, 619-625.

Ellis, F. R. \& Nunn, J. F. (1968). The measurement of gaseous oxygen tension utilising paramagnetism: an evaluation of the 'Servomex' OA 150 Analyser. British Journal of Anaesthesia, 40, 569.

Hermansen, L. (1973). Oxygen transport during exercise in human subjects. Acta Physiologica Scandinavica, Suppl. 399.

Kaijser, L. (1970). Limiting factors for aerobic muscle performance. Acta Physiologica Scandinavica, Suppl. 346.

Malhotra, M. S., Ramaswamy, S. S., Joseph, N. T. \& Sen Gupta, J. (1972). Functional capacity and body composition of different classes of Indian athletes. Indian Journal of Physiology and Pharmacology, 16, 301-308.

Novak, L. P., Bierbaum, M. \& Mellerowicz, H. (1973). Maximal oxygen consumption, pulmonary function, body composition and anthropometry of adolescent female athletes. Internationale Zeitschrift fur Angewandte Physiologie, 31, 103-119. 
Patrick, J. M. (1963). Calibration of an infra-red $\mathrm{CO}_{2}$ meter for measurement of alveolar $\mathrm{PCO}_{2}$. Journal of Physiology, $169,74 \mathrm{P}$.

Pugh, L. G. C. E. (1970). Oxygen intake in track and treadmill running with observations on the effect of air resistance. Journal of Physiology, 207, 823-835.

Rebuck, A. S., Jones, N. L. \& Campbell, E. J. M. (1972). Ventilatory response to exercise and to $\mathrm{CO}_{2}$ rebreathing in normal subjects. Clinical Science, 43, 823-867.

Rebuck, A. S. \& Read, D. J. C. (1971). Patterns of ventilatory response to carbon dioxide during recovery from severe asthma. Clinical Science, 41, 13-21.

Saltin, B. \& Åstrand, P-O, (1967). Maximal oxygen uptake in athletes. Journal of Applied Physiology, 23, 353-358.

Spryranova, S. \& Parizkova, J. (1971). Functional capacity and body composition in top weight lifters, swimmers, runners and skiers. Internationale Zeitschrift fur Angewandte Physiologie, 29, 184-194.

Taylor, H. L., Buskirk, E. \& Henschel, A. (1955). Maximal oxygen uptake as an objective measure of cardiorespiratory performance. Journal of Applied Physiology, 8, 73-80.

Watson, R. \& Devenney, K. (1972). Maximal oxygen uptake and related functions in male and female athletes. British Journal of Sports Medicine, 6, 53-64.

Wells, C. L., Scrunton, E. W., Archibald, L. D., Cooke, W. P. \& De La Morke, J. W. (1973). Physical working capacity and maximal oxygen uptake of teenaged athletes. Medicine and Science in Sports, 5, 232-238. 